In fact, the postoperative gastrointestinal symptoms in the patients treated by proximal gastric vagotomy were no different from those elicited from 50 patients selected at random from those attending surgical outpatients for other reasons. One other recent small series ${ }^{8}$ reported 5 out of 20 patients who had severe heartburn after proximal vagotomy, but this problem has not been highlighted by any of the other series.

No data are readily available to assess the long-term nutritional effect of proximal vagotomy, but the early changes of weight loss and anaemia seen after other forms of gastric surgery do not seem to be an important problem in the early years after this operation. Theoretically the other nutritional problems such as bone disease and steatorrhoea are unlikely to ensue, but this remains to be confirmed by long-term studies.

In conclusion, proximal gastric vagotomy is the logical development of peptic ulcer surgery: it prevents excessive acid production with minimal upset to other gastrointestinal functions. Its record in terms of mortality rate, gastrointestinal disturbances, and nutritional problems is good, but there is one nagging doubt regarding the problem of recurrent ulceration. Only as more surgeons take up the operation and further series are published will we know whether the great expectations are justified.

1 Goligher, J C, et al, British Medical fournal, 1968, 2, 781.

2 Johnston, D, et al, British Medical fournal, 1975, 1, 716.

3 Amdrup, E, et al, Annals of Surgery, 1974, 180, 279.

1 Grassi, G, et al, Surgery, Gynecology and Obstetrics with International Abstracts of Surgery, 1973, 136, 726.

${ }^{5}$ Kronberg, O, and Madsen, $\mathrm{P}$, cited in reference 7 .

6 Wastell, C, et al, British Medical fournal, 1972, 1, 28.

Temple, J G, and McFarland, J B, British Medical fournal, 1975, 2, 168.

${ }^{8}$ Kennedy, T, et al, British Medical fournal, 1975, 2, 301.

\section{Management of acute pancreatitis}

Acute pancreatitis is a relatively uncommon disease in Britain, affecting about 50 persons per million of the population annually. ${ }^{1}$ The clinical course is notoriously unpredictable; both the variability in the criteria for diagnosis and the difficulty in establishing the severity of the disease have made it hard to conduct satisfactory clinical trials of management and to compare data from different units. Furthermore, while biliary tract disease and to a less extent alcohol are implicated in many cases, the aetiology remains not clear in at least onethird of the patients in Britain. Perhaps it is not surprising that mortality figures ${ }^{23}$ range from $6 \%$ to $50 \%$.

The basis of the management of a patient with acute pancreatitis remains adequate analgesia, nasogastric suction, and prompt and complete replacement of fluid and electrolytes. In severe pancreatitis the plasma volume may be depleted by $30-40 \%$. The aim should be to achieve a minimum urinary flow of $30 \mathrm{ml}$ an hour. ${ }^{4}$ Some patients require replacement of calcium and magnesium ions, and vitamin replacement is probably useful in alcoholics. Blood and albumin are necessary in seriously ill individuals. The benefits of anticholinergic and antibiotic agents are less well established. Trapnell ${ }^{5}$ has questioned the value of routine antibiotic treatment, claiming that it does not prevent pancreatic abscesses, presumably the reason for initiating the treatment. Nasogastric suction is said to serve two purposes-to manage intestinal ileus and to reduce pancreatic stimulation-but the success of the latter aim is uncertain. It would be comforting to believe that anticholinergic therapy was more effective in reducing pancreatic secretion. Unfortunately this is not so, and the use of anticholinergic agents is as controversial in acute pancreatitis as in so many other gastrointestinal disorders. What is certain is the potential hazard of ileus, urinary retention, and tachycardia. ${ }^{2}$ The more frequent use of peritoneal dialysis, recognition of diffuse intravascular coagulation, and increased awareness of the syndrome of respiratory insufficiency requiring the early use of mechanical ventilation ${ }^{6}$ have added to effective medical care.

Treatment has been enhanced and at the same time complicated by the introduction of three allegedly specific regimens. We just do not know if they are effective. The oldest of these is the proteolytic enzyme inhibitor aprotinin (Trasylol), and there continues to be a lively debate over its therapeutic benefit. The majority opinion has been that it is ineffective, ${ }^{7-9}$ but a recent controlled trial ${ }^{10}$ on 105 patients gave promising results when large doses were used. Glucagon suppresses pancreatic secretion and increases splanchnic blood flow. Uncontrolled observations suggested that glucagon therapy was safe and induced relief of symptoms in pancreatitis. ${ }^{11} \mathrm{~A}$ study ${ }^{12}$ in rats failed to show any benefit from its use, but the difficulty of making analogies between animal studies of pancreatitis and human disease is well recognised. There is an urgent need for properly conducted clinical trials, and we have been told that the answer may well be forthcoming. ${ }^{13}$

The third regimen to excite interest is that of glucose and insulin infusion. The rationale behind this treatment is the concept that in acute pancreatitis activation of a hormonesensitive lipase present in abdominal adipose cells causes fat necrosis with ensuing abdominal pain and tenderness. Hallberg and Theve ${ }^{14}$ introduced treatment with 20 units of soluble insulin per litre of $5.5 \%$ glucose and $80 \mathrm{mmol}$ sodium infused at a rate of $300-400 \mathrm{ml}$ during the first hour with a total of 2 litres over 24 hours. The authors claimed rapid clinical improvement. Svensson's small double-blind controlled trial $^{15}$ of insulin and glucose showed that there was benefit during the initial 4-15 hours of treatment but that thereafter the patients were not at an advantage. This is another drug combination which requires evaluation by a larger study.

The role of early operation in acute pancreatitis is also controversial. In Britain most surgeons favour a nonoperative approach unless the diagnosis is uncertain, when all would agree that a laparotomy is mandatory. None the less claims have been made for early surgical intervention and drainage of the pancreatic bed or removal of gallstones and biliary tract exploration. Major pancreatic resections have been attempted, and even total pancreatectomy has been advocated for fulminant haemorrhagic pancreatitis : but these are hazardous procedures in critically ill patients and not surprisingly carry a high mortality rate. Recent studies suggest that early operative management has no advantages in acute pancreatitis. ${ }^{416}$

1 Trapnell, J, Annals of the Royal College of Surgeons of England, 1971, 49, 361. 2 Banks, P A, Gastroenterology, 1971, 61, 382.

3 Olsen, H, American fournal of Digestive Diseases, 1974, 19, 1077

Imrie, C W, and Whyte, A S, British fournal of Surgery, 1975, 62, 490.

5 Trapnell, J E, Annals of the Royal College of Surgeons of England, 1966, 35, 265.

${ }^{6}$ Ranson, J H C, Roses, D F, and Fink, S D, Annals of Surgery, 1973, 178, 75. ' Baden, H, et al, Scandinavian Fournal of Gastroenterology, 1969, 4, 291. ${ }^{8}$ Vestad, E, and Aakhus, T, Acta Chirurgica Scandinavica, 1970, 136, 147. 9 Parkash, O, Digestion, 1972, 7, 220.

10 Trapnell, J E, et al, British fournal of Surgery, 1974, 61, 177.

${ }^{11}$ Condon, J R, Knight, M, and Day, J L, British fournal of Surgery, $1973,60,509$.

12 Lankisch, P G, et al, Scandinavian fournal of Gastroenterology, 1974, 9,725.

${ }^{13}$ Welbourn, R B, and Cox, A G, British Medical fournal, 1974, 1, 244.

${ }_{14}$ Hallberg, D, and Theve, N O, Acta Chirurgica Scandinavica, 1974, 140, 138

15 Svensson, J-O, Scandinavian fournal of Gastroenterology, 1975, 10,487.

${ }^{16}$ Ranson, J H C, et al, Surgery, Gynecology and Obstetrics, 1974, 139, 69. 